\title{
'Economic Culture' as an Explanatory Tool in Transformation Research*
}

\author{
MAREK SKOVAJSA**
}

\begin{abstract}
This article reviews theoretical suggestions concerning the conceptualisation of economic culture that were made in a series of publications on the cultural dimension of post-communist transformation by the Institute for Research on Eastern Europe in Bremen. Analyses are made particularly of the points where culture on the one hand and institutions, social capital and civil society on the other overlap and differ and from these comparisons consequences are drawn for use of the concept of economic culture in transformation research. The article concludes that economic culture is a conceptual category in its own right, neither irreducible to the level of institutions, in the sense that institutional economics understands them, nor to social capital or civil society. If, moreover, economic culture is to be used as a tool for explaining socio-economic processes, its strict separation from institutions, social capital and civil society is essential.

Sociologický časopis/Czech Sociological Review, 2004, Vol. 40, No. 3: 363-378
\end{abstract}

An underestimated dimension? This obviously rhetorical question figures in the title of a book that, in 1999, opened a series of publications put out by the Institute for Research on Eastern Europe at Bremen University, all of which stemmed from interdisciplinary conferences that were organised by the Institute and dedicated to the task of contributing, by means of theoretical reflection and empirical analysis, to understanding the influence of the factor of 'culture' on the transformation process in Central and Eastern European countries. With 82 articles published in the five books in the Bremen series [Höhmann 1999, 2001, 2002; Höhmann, Fruchtmann and Pleines 2002; Höhmann and Pleines 2003], the number of contributions is indicative of how concentrated and sustained an effort this was to analyse the cultural co-determination of the transformation processes. The authors of the articles come from various German research institutions and also from a number of transition countries, mostly from Russia, but also from Poland and the Czech Republic.

As is the case with most collections of texts, and especially collections of contributions drawn from conferences, it is hardly possible to speak of a single tune

\footnotetext{
* The research was supported by the 6FP grant 'Eastern Enlargement - Western Enlargement. Cultural Encounters in the European Economy and Society after the Accesssion' headed by the Institute for Human Studies, Vienna and the Central European University, Budapest.

** Direct all correspondence to: Marek Skovajsa, Faculty of Humanities, Charles University, U kř́že 8, Praha 5-Jinonice, 158 00, Czech Republic, e-mail: skovajsa@soc.cas.cz.
}

(c) Institute of Sociology, Academy of Sciences of the Czech Republic, Prague 2004 
and even less so of a common set of positions on at least the most central topics in all the studies published in the Bremen series. This may be less of a surprise given that the subject matter that unites all five volumes is a concept as ambiguous and contested as culture, or more specifically culture in its role as a factor in economic life in general and in the economic transformation of post-communist societies in particular. The great variation in approaches, views and evaluations, however, is rather more a virtue than a vice. It allows, at any rate, for a fruitful confrontation of different views, which are often conditioned by the different stereotypes that have evolved in various social science disciplines or strands of research and maintained by them in sterile isolation, away from the incentives stemming from developments in other branches. On the other hand, the reader might feel entitled to demand a more unifying principle underlying a series than just a common topic, and perhaps also some indication of which texts form, so to speak, the flagship contributions representative of the whole project. The rather loose organisation of the volumes, although they give preference to theoretical contributions over case studies and empirical analyses, does not seem to correspond to such concerns. The reader is thus left with the option of digging into the volumes individually in search of exceptional texts in the field of theory and empirical research on economic culture.

As far as theoretical reflection is concerned, the best introductory texts can be found in the first volume [Höhmann 1999], especially those by Carsten HerrmannPillath and Stephan Panther, who both attempt, each in their own way, a definition of the research field of the economic-cultural analysis of the transformation, while they also discuss available methods and warn against the pitfalls that lay in wait for less cautious researchers. The most systematically organised block of theoretical articles can be found in the second volume [Höhmann 2001], where different approaches to the study of transformation from the viewpoint of economic culture are portrayed and, in varying degrees, adapted to the demands and requirements of transformation research. Along with institutional economic studies by Joachim Ahrens and Uwe Mummert the block contains studies on the political-cultural research on transformation (Stefan Garsztecki), the concept of social capital as a potential category in economic culture research (Bernhard Lageman) and civil society as an integrating cultural concept (Stephan Panther). It is especially these theoretical contributions that form the point of departure for the discussion presented in the later parts of this review. The two theoretical texts in the latest volume [Höhmann and Pleines 2003] by Helmut Leipold, Carsten Herrmann-Pillath and Christian Hederer are dedicated to conceptualising the way culture exerts an influence on the economy from the perspective of evolutionary institutional economics.

Alongside theoretical ruminations on what economic culture is and how it can be used in transformation research, the five volumes discussed here also contain a wealth of empirical studies dealing with individual topics, which, to do justice to the authors of the respective texts, warrant specific mention: in the first place, various aspects of the Russian economic culture are addressed, including the culture of Russian 
entrepreneurs and economic elites, corruption and informal networks, tax-related behaviour (a section of one book [Höhmann 2002] and one entire volume [Höhmann, Fruchtmann and Pleines 2002] are dedicated to this particular topic) and the economic policy of the state. The Russian and Polish economic cultures are the subject of an interesting section on 'Mirroring the Economic Transformation in Science, Joke and Literature' [Höhmann 2002], which, with its focus on artefacts that belong to the realm of so-called high culture, opens up to economic-cultural research on transformation a perspective largely absent from literature. Finally, other sections are dedicated to: the role of culture in the practical economic relationships between 'West' and 'East'; the contribution of cultural geography to transformation research; the cultural dimension of regional development in post-communist countries; cultural influences on economic policies in Poland and the Czech Republic and cultural aspects of the break-up of Czechoslovakia.

The sheer breadth of issues addressed in the volumes from the Bremen series makes it very difficult for a reviewer to cover all of them in a single review. The already mentioned generosity and tolerance on the part of the editors with regard to differences in the approaches adopted by individual contributors makes it impossible to argue outright for or against a single position as representative of the whole project as such in any particular area it is concerned with. The remaining sections of this review article are therefore dedicated solely to the discussion of, in my view, some of the highly interesting theoretical suggestions regarding the interpretation of the central concept of culture put forth by the participating researchers. I will attempt to insert these into broader theoretical contexts and, in doing so, push the whole debate about economic culture and its role in the transformation process towards greater clarity and articulacy. This will occasionally involve the elucidation of some of the shortcomings that seem to me to be inherently present in many attempts to develop a conceptual framework for the study of economic culture which would enable it to profit from the results achieved in closely related fields, such as institutional economics or sociological research on social capital.

The task of assessing the quality and innovativeness of empirical studies dealing with different aspects of the cultural conditioning of the economy in various transition countries can be more fruitfully coped with by specialists on particular countries or areas, and thus it will remain outside the scope of this review.

\section{Once again: what are we talking about when we talk about culture?}

Not only may one start, one may also end with this notoriously difficult question. The authors of the theoretical contributions on culture in the volumes reviewed here know this well enough. The more valuable then is their effort to come up with, once more, viable, unambiguous and operationalisable conceptions. What might be a source of some confusion, however, is that the theoretical articles in the various volumes try to link or identify culture with such diverse concepts as civil society, formal and/or in- 
formal institutions, cognitive models and social capital. Such breadth of scope can be understood as a result of a concerted effort to find a truly encompassing definition of culture that well meets the needs of transformation research. On the other hand, this endeavour may quite easily be exposed to objections of eclecticism. It is therefore no less important to spell out the essential differences between these concepts than it is to emphasise a certain level of interconnection between them. I will address the two issues of their deep similarities and insurmountable differences below. But first the central problem of the definition of culture must be briefly discussed.

Innumerable attempts have been made to define culture in a manner acceptable throughout the social science community, but since a full consensus has never been achieved, it seems to be the first obligation of each and every author dealing with cultural factors to make explicit his/her own understanding of culture. In the volumes under review here this obligation is fulfilled most explicitly in a theoretical article by Stephan Panther, who endorses a conception of culture common in the field of cognitive social anthropology and defined as a "learned system of meanings (and evaluations) shared by a group of actors" [Höhmann 1999: 24]. Since this same cognitivist conception of culture is later modified (by Panther himself, see below, or by Stefan Garsztecki who propounds a Geertzian, 'thick description' perspective [Höhmann 2001: 67]) or outright criticised (by Helmut Leipold in an article on culture from the viewpoint of institutional economics [Höhmann and Pleines 2003: 16-18]) there does not seem to be much of a common ground or basic tonality where the authors converge in their thoughts on culture. No attempt at a systematic derivation of the concept of culture from general theoretical premises of whatever kind can be found in any of the volumes; all theoretical contributions are rather proposals for the creative appropriation of some already existing influential view of culture, such as the cognitivist one presented by Panther. On the other hand, the thoughts of the authors while reviewing existing conceptions of culture and offering their own commentaries on them are in no way theoretically naïve, nor do they betray an ignorance of recent developments in the discussions about culture in sociology, economics, political science and social anthropology.

Above all, it must be acknowledged that most authors are well aware of the risks inherent in both theorising and researching the presumed cultural determinations in social and economic life. This is especially true of the contribution by Carsten Herrmann-Pillath in the 1999 volume, in which the author takes exemplary precautions against the many mistakes that are otherwise typical in cultural analysis. In my eyes those worth mentioning are: the impossibility of relating culture as an explanatory factor to individual behaviour; the false location of culture on one level, most typically that of the 'nation'; the unproductive equation of culture with 'tradition' and 'history', concepts that are themselves in need of clarification; the disregard of the fundamental fact that the observation of culture always occurs through the eyes of an observer, who is herself prisoner to some cultural scheme. This last property of cultural analysis is in itself sufficient to set clear cognitive limits to cultural analysis of economic and social behaviour. Yet, the debates about cul- 
ture in the social sciences are to a large extent debates about where these limits are situated and how, given these limits, the concept of culture can be made fruitful in the analysis of social reality.

I now turn to the discussion of what I consider to be the crucial problem in the theoretical reflection of economic culture presented in the volumes under consideration, namely clear demarcation of the meaning of the term 'culture' in contrast to the meanings of other concepts with which it, as some authors suggest, commingles or to which it is even identical.

\section{Culture vs. institutions}

Typically for research on economic transformation, the attempts at ascribing a more specific meaning to culture are at the same time attempts to make it partly or fully coincide with some more familiar concepts used in the analysis of economic processes, which, it could be argued, are just other names for culture preferred in various social science disciplines for reasons that have to do with the contingencies of their historical development. In the volumes of the Bremen series, I found three such attempts that are in my opinion worth discussing here. They are the proposals to establish close links between culture and institutions, culture and social capital or culture and civil society.

It is more than natural that within the research on economic transformation ways are sought to reconcile the culturalist strand with the older and more established approach of institutional economics. This is attempted in the present volumes by a number of authors (Uwe Mummert, Eckehard Rosenbaum, Joachim Ahrens, Helmut Leipold). Although the issue of how culture is related to the central concepts of institutional economics is avoided by all these authors except for Leipold, it seems in all cases that such approximation between the two approaches is meant to occur through some kind of fusion of culture and institutions.

The case of institutions is extremely interesting. Of course, the inclusion of institutions - as patterns of behaviour - among the component parts of culture has long been part of the common stock of knowledge in some streams within social anthropology (for an older but highly influential classification see Kroeber and Kluckhohn [1963]). Institutional economics, on the other hand, understands institutions rather as rules, both formal and informal, that constrain individual behaviour. From the viewpoint of this thriving and well established discipline, the identification of culture with institutions-as-rules, or the inclusion of the latter in the former, would make any culturalist approach look redundant in the first place and marginal in the second. For this reason, it must be asked whether a view of institutions and culture that makes a distinction between the two is tenable, in the first place, and, further, if it can be of any potential benefit to economic and social research in general and to the research on transformation in particular. In other words, we should ask if there is any added value to the culturalist approach that accords central importance 
to culture as opposed to institutional economics, emphasising the role of institutions-as-rules in our understanding of economic processes.

Unlike the views that seem to be implicitly present in some contributions in the volumes, and unlike the above-mentioned currents in social anthropology, I believe that it is essential to sustain a clear-cut distinction between institutions and culture. One reason is that the view of institutions in institutional economics is too narrow to cover the entire sphere of culture. Another reason is that the distinction between culture and institutions acquires an especial relevance in transformation research, because in the processes that constitute the economic, political and social transformation, institutions are transposed from societies of a certain cultural type to societies endowed with a culture that is in many respects different.

Let me start with the oversimplification into which institutional economics has fallen by using too narrow a view of institutions and their operations in the broader social context. The parsimonious definition of institutions as "the rules of the game in a society or ... humanly devised constraints that shape human interaction" [North 1990: 3] might serve well the tastes of economists brought up with the mainstream way of thinking in their discipline. However, the concept of institutionas-rule or constraint, although it covers a certain crucial aspect of the social context of economic behaviour, lacks the potential for a deeper analysis of how and why actors behave the way they actually do. The conception of North and others is of rules as norms, according to which actors organise and shape their interaction. And although there can be no doubt that rules in this sense are an essential part of every culture, there seems to be a wide range of objects that belong also to culture but are rather difficult to interpret as rules of interaction. For instance, there are symbols, narratives and schemes of perception that serve individuals in finding their bearings in the world, by reducing its complexity, and also in constructing their own identity and identifying other objects, but which are not rules of interaction proper - notwithstanding their clearly inter-subjective, and hence social nature. To be sure, such cognitive and perceptual frameworks also play a role in the formation of rules of interaction. But to reduce culture to such rules would be to ignore that human beings not only behave or interact, but also perceive, interpret, imagine, plan, intend, hesitate and do all kinds of other things that cannot be described as interaction in the usual sense. And since those non-rule-like components of culture exert an influence on its rule-like parts, any attempt to explain or understand behaviour that is based solely on knowledge of rules of interaction is in itself insufficient. Not everything there is to culture is rules or sets of rules, unless we overstretch the meaning of 'rule' as a socially enforced instruction for interaction with others which is what North and other institutional economists have in mind - and extend it much further to denote any principle of an agent's activities, whether they involve other persons or not.

This view does not contradict North's treatment of culture that is offered in the chapter dealing with informal institutions where he takes culture to mean "transmission from one generation to the next, via teaching and imitation, of knowl- 
edge, values, and other factors that influence behavior" [North 1990: 37; quoting Boyd and Richerson]. Although he also asserts here that informal constraints are part of what we call culture, an equation between informal constraints (or, informal institutions-as-rules) and culture is never made.

Furthermore, the evolutionary understanding of the genesis and selection of institutions-as-rules strongly present in institutional economics (and drawn on in the Bremen volumes) obviates the need to specify the ways in which individuals consider them as binding for themselves. In other words, the evolutionary perspective enables us to see that, and to see why certain institutions have asserted themselves in the struggle for survival while others perished, but it does not tell us much about how the victorious institutions are incorporated into the ways of thought and action - or simply culture - of individual members of a given group. This problem perhaps touches on a major contrast between the economist's perspective (including that of the institutional economist) and the culturalist's perspective on economy and society: the economist is interested in 'culture' only instrumentally, as a means of increasing the explanatory force and scope of his/her models, but these are built around some basic premises (self-interested and rational individual actors, selection through competition) which are culturally conditioned and therefore questioned and thoroughly relativised in any truly culturalist theory.

The problem of the insufficient depth of analysis of culture in institutional economics does not disappear when the widely used distinctions of formal/informal or external/internal institutions are introduced. Both dichotomies hinge on the presence/absence of a second-order institution, most typically the state, which enforces the observation of certain rules. Yet, if our understanding of rules is poor, in so far as concerns their substance and place in the make-up of a culturally constructed and meaningful world in which individuals act, then it will remain poor however complex the structure of mutually reinforcing and interdependent sets of rules may turn out to be.

It is also important to note that the concept of institutions-as-rules, far from being an analytically simple one, can be deconstructed into its more fundamental constituent parts. That rules are followed requires some kind of emotional, moral or rational motivation on the part of the agent, which cannot be reduced to the perception of expected benefits and losses. On the contrary, it requires a richer concept of culture to be fully grasped. The motivation, in its turn, presupposes some emotional, moral or rational attachment to certain objects that are commonly referred to as values [Deth and Scarbrough 1995: 22]. I believe that it is more sensible, and allows for deeper levels of analysis, to talk about human behaviour in terms of values pursued than in terms of rules followed, without losing sight, for that matter, of the disconcerting vagueness of the concept of value. The talk about values moves us away from the narrowly defined area of institutions-as-rules towards that of culture.

To sum up, the first line of argument against the conflation of culture and institutions as conceptualised by institutional economics has shown that the latter's view of institutions is too narrow. This poverty of understanding is an advantage 
from the point of view of an explanatory science, which must first solve the problem of the reduction of complexity vis-à-vis reality before it can offer any scientifically sound accounts of what is going on in the social world. It is entirely acceptable as long as this discipline does not fail to achieve the goal it has set itself and is able to produce solid explanations and descriptions. Once this ceases to be the case, the reduction of complexity must be undertaken anew, this time in a less radical way, allowing for less simplification. Something of this kind is happening, in my view, with the rising interest in the concept of culture among the social sciences in general and in economic sociology in particular.

The second grounds for substantiating the conviction that culture and institutions must be kept apart, as two separate kinds of social objects, is, in my view, the concern about analytical clarity in the area of research on transformation. As already mentioned, transformation has also been an exercise in institutional engineering, where the institutions that had evolved over time in developed economies were to be transposed into the potentially fertile, yet uncultivated field of the postcommunist societies. An essential observation worth making here is that unless we follow an excessively simplistic view of this process, it involves the transmission of both formal and informal institutions. As is well known, the performance of transition countries in adopting these institutions varied considerably, and it is certainly no exaggeration to say that it has been precisely this observation that provided strong incentives for the rapid increase in the level of interest in the cultural conditioning of economic and political processes. In other words, culture can be seen as the factor that explains variations in the capacity for institutional transformation across countries. The identification of culture with institutions would, of course, make such use of culture for explanation highly problematic.

It must be noted here that there is a certain amount of ambiguity in the meaning of the term 'institutions', which makes it such a frequent source of misunderstanding and confusion. In the context of transformation research, and even more clearly in the context of preparations for membership in the European Union, institutions mean, first and foremost, the formal structures and organisations that had to be created as a part of the effort to build an 'institutional infrastructure' for a functioning market economy and successful integration into the EU. This use of the term might have given rise to two instances of confusion. First, institutions are frequently identified with organisations, a practice as common as it is misleading, once any serious analysis is to be undertaken. Second, institutions are sometimes reduced to the idea of formal institutions, leaving the hugely important field of informal institutions unattended.

This last ambiguity brings us to the question of whether culture, after all, cannot be identified with informal institutions. The authors of a highly interesting theoretical introduction to the study of Polish economic culture seem to offer an affirmative, albeit hesitant, answer to this particular point [Kochanowicz and Marody 2003: 346-7]. However, I do not think it is wise to equate culture with informal institutions for reasons already expounded in the discussion about the weaknesses of 
the understanding of institutions in institutional economics. Unless the definition of informal institutions is extended beyond that according to which these are informal rules of interaction, then there is more to culture than merely (informal) institutions. Kochanowicz and Marody, at the end of the day, also seem to favour a broader conception of culture, since their definition of economic culture includes value systems, cognitive schemes and patterns of behaviour [ibid. 349].

It remains to be seen what is to be gained or lost if the genuinely culturalist perspective on economic research is adopted (as opposed to one that chooses the concept of institutions-as-rules for its point of departure). Since institutions and culture are taken in this perspective to be two different entities, this question makes sense. The simplest answer seems to be this: by adopting an economic culture position one gains in terms of analytical scope and the richness of material studied, but loses in explanatory potential. ${ }^{1}$ In a culture, values, norms, identities, symbols and shared meanings form a unique complex, which, although not necessarily internally consistent, offers the individuals socialised in it instructions on how to behave in any typical situation that might arise. Accounting for the behaviour of groups in terms of culture is, however, much more difficult than doing so by relying on the more reductionist concept of rules. One must accept that the price for increased theoretical sophistication and, I believe, greater approximation to reality is a reduction in the usefulness of the approach for generating simple and elegant explanations for human behaviour. If I may here employ terms borrowed from late 19th century neo-Kantian philosophy - culture seems more suited to idiographic than nomothetic use.

\section{Culture vs. social capital}

Unlike institutions-as-rules, which might be thought of as overlapping if not coterminous with culture, the concept of social capital can be interpreted in ways that preclude any possible synthesis with culture. The problem here is that social capital is a concept no less ambiguous than culture and, as such, has also been ascribed a great variety of meanings, some of them mutually exclusive or incompatible. At least two different conceptualisations of social capital are worth recalling: one, proposed by Coleman, considers social capital as stemming from the properties of social structure; the other, presented in the much acclaimed work of Putnam, Leonardi and Nanetti [1993], I will here call 'mixed', because to some extent it incorporates both

\footnotetext{
${ }^{1}$ One can draw a parallel between this approach and the use of the concept of cognitive models that is also discussed in some theoretical studies of the Bremen series. Institutional economists came up with the concept of cognitive models to cover the beliefs of the actors about the qualities and regularities of the world they live in that co-inform their behavior [North 1990: 8]. Cognitive models, without any doubt, bring this strand of research much closer to the culturalist perspective than the overly reductionist concept of rules as discussed above. Yet, the price it has to pay for it is again the same: a loss of explanatory power.
} 
structural and cultural elements. It is of course between social capital as a property of the social structure and culture that the issue of incompatibility arises. In the face of proposals to resort to the concept of social capital in the framework of cultural analysis such as that presented in the Bremen series (Lageman in [Höhmann 2001]), one should ask whether social capital can be related to culture in any meaningful way, how this can be done, and what the potential benefits of this step for our understanding of economic and social processes could be.

According to Coleman, social capital "constitutes a particular kind of resource available to an actor" that unlike other forms of capital "inheres in the structure of relations between actors and among actors. It is not lodged either in the actors themselves or in physical implements of production" (emphasis M.S.) [Coleman 1988: S98]. That said, it is clear that social capital in the sense attributed to it by Coleman cannot be considered to be a synonym for culture or a segment of it. For culture, after all, as a system of shared meanings, beliefs etc., is lodged also, albeit not exclusively, in the actors themselves. Coleman follows Bourdieu both in stressing the relational or groupmembership aspect of resource mobilisation by individuals in case of the social capital and in keeping it clearly distinct from the form of capital carried by and in individuals, which both authors, quite significantly for us, call cultural capital.

In my view what is important is the emphasis laid on the purely structural-relational content of social capital: it can be observed and measured in absolute independence of the properties that may be located in the individual, including other forms of capital, even if, of course, the conditions whereby it is acquired and accumulated are strongly dependent on the amounts of other types of capital in his/her possession. Were the term social capital to denote something other than accumulated resources derived from an individual's position in group and network structures, its semantic field would necessarily overlap with those of other types of capital, a circumstance that would make it redundant and confusing. One should, therefore, defend the isolation of social capital from other forms of capital in Coleman's sense on the grounds of its analytical clarity.

The use Putnam et al. make of the concept of social capital is much more prone to misunderstanding and ambiguity. The reason for this lies in his insistence on the impossibility, or at least the unproductiveness, of separating culture from structure: “ .... attitudes and practices constitute a mutually reinforcing equilibrium. ... In this context, the culture-vs.-structure, chicken-and-egg debate is ultimately fruitless" [Putnam, Leonardi and Nanetti 1993: 180-1]. This view forms the background against which one must contemplate Putnam's central concept of civic community, which denotes a set of mutually reinforcing cultural and structural features: "The norms and values of the civic community are embodied in, and reinforced by, distinctive social structures and practices" [ibid. 89]. Even if social capital in Putnam et al. is mostly considered to be a structural property (cf. Tatur [Höhmann 2001: 208]), its definition as "features of social organization, such as trust, norms, and networks" [Putnam, Leonardi and Nanetti 1993: 167] makes it a clearly ambiguous concept, stretching simultaneously over portions of both the structural and cultural 
sides of social reality. This is not surprising at all in light of the just quoted conviction of Putnam et al. that the distinction between culture and structure misses the point of social analysis. It might have been this ambiguity, too, that led some authors to praise the work of Putnam et al. as "a stunning breakthrough in political culture research" [Laitin 1995: 171] (emphasis M.S.), although its extensive reliance on the analysis of social structures is undeniable.

It is possible, of course, to accept the use of the concept of social capital by Putnam et al. as a structural-cultural feature of administratively efficient and civically active societies, but one should not fail to notice the lack of conceptual and analytic clarity in comparison to Coleman's definition. On the other hand, it is undeniable that their conceptualisation has achieved, at the price of reduced analytical transparency, a better approximation to real social life, avoiding at the same time the necessity of resolving the notoriously unsolvable puzzles posed by the interdependence between cultural and structural variables.

Turning back to the question of how culture and social capital can be synthesised and what beneficial effects this might have for research on economic transformation, I would like to argue that the best answer is that a synthesis is not possible or even desirable and that it is more important to clear up the confusion than to attempt to establish close links where there is a difference of order. This certainly holds for Coleman's structural definition of social capital. As to the position of Putnam et al., we have seen that their entire approach is resolutely opposed to any attempt to resolve the mystery of how culture and structure influence each other. Therefore, it does not seem sensible to put their concept of social capital at the service of cultural explanations for such processes that so deeply affect the social structure as the post-communist transformation.

If social capital is a structural or, at best, a mixed structural-cultural feature, then it should not be thought of as part of economic culture. Its clear separation from culture can, however, enhance the scope of potential explanatory tasks for the concept of culture. Above all, the question should be asked as to the ways in which social capital as membership in groups and networks can be culturally co-determined. In other words, are there cultural causes behind the differing levels of intensity of associational life, the density of personal networks and the frequency of occurrence of any type of social group, which could serve as a source of social capital for its members? The book by Putnam et al. on Italy produces evidence of the impact of culture on the structural features of Italian regions, although the historical naivety of his approach has been repeatedly exposed to strong criticism [e.g. Tarrow 1996]. But it is one thing to have evidence of the strong cultural conditioning of social capital in its structural meaning, and another to deny its distinctiveness as opposed to culture. Without a doubt the study of the cultural sources and the cultural effects of social capital is an immensely promising field of research, in spite of all the conceptual ambiguities that seem to abound in this strand more than elsewhere. Yet, it is also to be regretted that in spite of the extreme popularity of such keywords as 'trust' or 'civic community' in social science literature, not enough has 
been done so far to overcome the confusion surrounding the operation and mutual interdependence of structural and cultural factors that have bearing upon them.

\section{Culture vs. civil society}

A third attempt at conceptual synthesis that I found highly inspiring, but also highly problematic, in the volumes under consideration here is that between culture and civil society. In the contribution most expressly focused on civil society a plea is made for its identification with a culture (Panther in [Höhmann 2001]). A necessary precondition for this is the expansion of the concept of culture in such a way as to include behaviour or, as Panther refers to it, the structure of interactions. As in the case of social capital, this seems to me perfectly possible, provided the researchers are well aware of the risk of potentially indiscriminate use of culture and avoid any fallacious conclusions that they might be tempted to derive from it. Yet, once again, what is the benefit for economic culture (or, for that matter, any culture-oriented research) of identifying culture with structure? Civil society without a doubt means in the first place a certain type of social structure. When talking about civil society as a culture, two dimensions become deeply intermingled which for analytical purposes it has proved useful to keep apart. Something gets lost from the analytical power of the concept of culture and it is entirely unclear in what way it could be used for explanations in the study of any social process with bearing upon social structure.

If, on the other hand, the narrower understanding of culture is preserved, talk about civil society as a (civil or civic) culture makes sense, as long as what is meant is that civil society needs a certain specific type of culture to support it and to cultivate its members with the values, norms, beliefs etc. that are indispensable for its constitution and maintenance. I see no chance of going further than this and no cogent reason to conflate civil society and culture. A perhaps remotely similar attempt, that of Jeffrey Alexander [1993], did not venture as far when it proposed the discourse of civil society as the subject matter of cultural studies, conversely emphasising the preservation of the fundamental distinction between culture and structure.

One can only agree with Panther's conceptualisation of civil society as forming one of several social sub-systems, without any claim to superiority over others, most notably the state. This perspective enables one to see how civil society, or, more exactly, the culture supportive of civil society, might establish itself as a relevant category of the cultural analysis of the economy. This is so for a number of reasons that become visible on the structural level, hence the usefulness of a way of reasoning that follows simultaneously structure and culture as two distinct, yet inseparable layers of social reality. First, civil society partly overlaps with the economic sphere, and, second, there are beneficial input and output functions mediating between civil society and the economy, which require a supportive cultural environment in order to become fully operative [cf. Höhmann 2001: 100-2]. Third, the 
study of the way economic culture and economic behaviour are interrelated might proceed analogically to research on civic culture in relation to civil society, in which case the more developed research on civil society and its culture might serve as a rich source of ideas and approaches for research on economic culture. Finally, the culture of civil society is, like any other sectional culture, embedded in and overlaps with the broader societal culture as such, with all its rich structuring and complexity, and thus it contains elements of the latter that, because of an analogous immersion of the economic sub-system in the social system as such, are also 'parts' of the economic culture.

\section{Conclusion: culture as irreducible to institutions, social capital and civil society}

There is little need to prove that the approach to post-communist transformation in its economic and also its political dimension, from the vantage point of culture, is legitimate as a residual analytic procedure, ready to assist the puzzled researcher whenever supposedly more reliable approaches fail to bring him/her adequate results. For this I think enough evidence has been gathered in the books reviewed, and elsewhere, through the many examples of the undeniable influence of cultural factors on the functioning of transforming societies. Yet it takes more to demonstrate that the cultural approach can yield explanations that are sufficiently robust as to become a legitimate fully-fledged alternative route leading to a deeper understanding of the transformation processes. This cannot be done without an adequate revision and adaptation of the concept of culture, something that has been to some extent undertaken in the series of books reviewed here. While leaving aside the supremely important questions of operationalisation and methodology, I have pointed to some problems and ambiguities linked to such revisions of culture which aim at bringing it closer to other key concepts frequently used in socio-economic literature. It remains to be seen if the respective alliances between culture and these other concepts can be employed as an instrument of explanation with any cognitive gain whatsoever in the study of cultural influences on economic processes.

It might be useful to first recall the two criteria proposed by DiMaggio for even the possibility of a successful cultural explanation of economic phenomena: "To establish a 'cultural effect' ... [f]irst, one must demonstrate that individuals or collective actors with some specific kind of culture behave differently than others without it. ... Second, one must demonstrate that such differences do more than mediate structural or material influences" [DiMaggio 1994: 28]. Taken together, these two criteria represent the minimum set of requirements that any cultural account must comply with. Let me call the first of them the criterion of comparative behavioural difference, and the second the criterion of the irreducibility of culture.

Culture as institutions. If institutions (all or just informal ones) are taken to be the core of culture, the question of the influence of culture on behaviour becomes obscured, to say the least. On a level where institutions are identified exclusively 
with the rules of behaviour, the criterion of comparative behavioural difference becomes tautological and irrelevant. All observable differences in behaviour can be accounted for by the different rules underlying them, and since new rules can be constructed for every previously unknown behavioural difference they can be multiplied ad infinitum. Yet, we do not have any other access to rules than through behaviour, hence no non-circular explanations are possible. Nor can we learn anything about the way rules become binding for individuals. If, on the other hand, institutions are patterns of behaviour rather than mere rules, then either representatives of different cultures cannot behave differently if they share the same institution, a premise that has been negated many times in the course of institution-building throughout transformation countries, or, if, defying this definition, they behave differently vis-à-vis a certain institution, then their different behaviour cannot be explained in terms of culture.

Culture as social capital. A conflation of culture and social capital contradicts the criterion of the irreducibility of culture. Taken in the meaning Coleman accorded it, social capital is a structural property, and any explanation in terms of culture qua social capital is thus an explanation in which culture only mediates (or even more accurately is merely a label for) a structural influence. The same is also true if we use the term social capital according to the meaning Putnam et al. ascribed it, with all the conceptual ambiguities commented upon earlier. On the other hand, if social capital is taken properly to mean cultural aspects, such as civic norms, values etc., then both criteria seem to be fulfilled, but the issue of the term's superfluity arises, since it becomes indistinguishable from culture.

Culture as civil society. Since an alliance between culture and civil society requires that culture be taken in the broader sense, including institutions and social structures, it is exposed to both preceding criticisms. As is the case with institutions-as-rules, one can invent as many cultures as there are different behaviours to account for them, but the central problem of how these differences can be explained by independently observable variables is left unanswered. The criterion of the irreducibility of culture is also clearly not met, for culture is redefined as a culturalstructural hybrid.

The discussion presented in this article intended to show that a good deal of work has yet to be done in the field of conceptual clarification before the instruments in the toolkit of research on economic culture are as efficient as they may be required to be in order to be put to use in analyses of economic transformation or any other ambitious purpose. The Bremen volumes have made a significant contribution to this endeavour by providing a rich variety of answers, however partial they might be, to the central questions of this branch of research. They are also highly inspiring owing to the manner in which they approach culture empirically and to the way in which they encourage an interdisciplinary way of thinking about the postcommunist transformation of the economy and society. 
MAREK SKOVAJSA studied political science at the Faculty of Social Sciences of Charles University, Prague. He lectures on social and political theory at the Faculty of Humanities and participates in the research projects of the Department of Economic Sociology at the Institute of Sociology of the Academy of Sciences of the Czech Republic. Since 2001 he has been editor-in-chief of the Czech edition of Sociologický časopis/ Czech Sociological Review. His research interests focus on political and economic culture, civil society and European integration.

\section{References}

Alexander, Jeffrey C. 1993. "The Discourse of American Civil Society: A New Proposal for Cultural Studies." Theory and Society 22: 151-207.

Bourdieu, Pierre. 1986. “The Forms of Capital." Pp. 241-58 in Handbook of Theory and Research for the Sociology of Education, edited by John G. Richardson. New York: Greenwood Press.

Boyd, Robert and Richerson, Peter J. 1985. Culture and the Evolutionary Process. Chicago: University of Chicago Press.

Coleman, James S. 1988. "Social Capital in the Creation of Human Capital." American Journal of Sociology 94 (Supplement): S95-S120.

Deth, Jan W. van and Elinor Scarbrough. 1995. "The Concept of Values." Pp. 21-47 in The Impact of Values. Beliefs in Government Volume Four, edited by Jan W. van Deth and Elinor Scarbrough. Oxford: Oxford University Press.

DiMaggio, Paul. 1994. "Culture and Economy." Pp. 27-57 in Handbook of Economic Sociology, edited by Richard Swedberg and Neil J. Smelser. Princeton: Princeton University Press.

Höhmann, Hans-Hermann (ed.) 1999. Eine unterschätzte Dimension? Zur Rolle wirtschaftskultureller Faktoren in der osteuropäischen Transformation. Bremen: Edition Temmen.

Höhmann, Hans-Hermann (ed.) 2001. Kultur als Bestimmungsfaktor der Transformation im Osten Europas. Konzeptionelle Entwicklungen - empirische Befunde. Bremen: Edition Temmen.

Höhmann, Hans-Hermann (ed.) 2002. Wirtschaft und Kultur im Transformationsprozeß. Wirkungen, Interdependenzen, Konflikte. Bremen: Edition Temmen.

Höhmann, Hans-Hermann, Jakob Fruchtmann and Heiko Pleines (eds.) 2002. Das russiche Steuersystem im Übergang. Rahmenbedingungen, institutionelle Veränderungen, kulturelle Bestimmungsfaktoren. Bremen: Edition Temmen.

Höhmann, Hans-Hermann and Heiko Pleines (eds.) 2003. Wirtschaftspolitik in Osteuropa zwischen ökonomischer Kultur, Institutionenbildung und Akteursverhalten. Russland, Polen und Tschechische Republik im Vergleich. Bremen: Edition Temmen.

Kochanowicz, Jacek and Mira Marody. 2003. “Towards Understanding the Polish Economic Culture." Polish Sociological Review 4: 343-368.

Kroeber, A.L., Kluckhohn, Clyde 1963/1952. Culture. A Critical Review of Concepts and Definitions. New York: Random House.

Laitin, David D. 1995. "The Civic Culture at 30." American Political Science Review 89 (1): 168-173.

North, Douglas C. 1990. Institutions, Institutional Change and Economic Performance. Cambridge: Cambridge University Press. 
Putnam, Robert D., Robert Leonardi and Raffaella Y. Nanetti. 1993. Making Democracy Work. Civic Traditions in Modern Italy. Princeton: Princeton University Press.

Tarrow, Sidney. 1996. “Making Social Science Work Across Space and Time: A Critical Reflection on Robert Putnam's Making Democracy Work." American Political Science Review 90 (2): 389-397. 